\title{
Effect of Branched and Straight Chained Alcohols on Performance of Crude oil Demulsifiers
}

\author{
*11ODISU, T; ${ }^{2}$ EDOMWONYI-OTU, LC ; ${ }^{3}$ BASSEY, EN; ${ }^{1}$ OHIMOR, EO \\ ${ }^{I}$ Department of Chemical Engineering, Federal University of Petroleum Resources, Effurun, Nigeria \\ teddyodi2002@yahoo.com; ohimortog@gmail.com \\ ${ }^{2}$ Department of Chemical and Petroleum Engineering, Delta State University, Oleh, Nigeria \\ Lawrence.edomwonti-otu.11@alumni.ac.ucl.uk \\ ${ }^{3}$ Department of Chemical Engineering, Akwa Ibom State University, Ikotakpadem, Nigeria \\ enbassey@yahoo.com \\ * Corresponding Author Email: teddyodi2002@yahoo.com
}

\begin{abstract}
Unwanted crude oil emulsions occur in many stages of oil production, transportation, and processing. The huge cost resulting from corrosion of transport system and production facilities, because of the presence of water is a major challenge to the oil industry and the global economy. However, the addition of alcohols to demulsifiers has been reported to enhance their efficiency in removing water from emulsions. There is therefore the need to identify the best type of alcohols and optimize this process of addition. Consequently in this work, the effect of different straight and branched chain alcohols on the performance enhancement of demulsifiers was investigated using four different crude oil emulsion samples. The results showed that straight alcohols performed better when compared to branched chain alcohols under all conditions of temperature. This may be due to their slow mobility particularly in stable emulsions.
\end{abstract}

\section{DOI: https://dx.doi.org/10.4314/jasem.v23i1.10}

Copyright: Copyright (c) 2019 Odisu et al. This is an open access article distributed under the Creative Commons Attribution License (CCL), which permits unrestricted use, distribution, and reproduction in any medium, provided the original work is properly cited.

Dates: Received: 31 December 2018; Revised:22 January 2019; Accepted 26 January 2019

Keywords: Crude Oil, Emulsion, Emulsifiers, Demulsifiers, Alcohols

Today, crude oil is one of the most important constituents of the reservoir fluids because of its huge economic value. The fluid constituents of oil wells as well as the maturing nature of old wells necessitate that crude oil is seldom produced alone because it is generally commingled with water and other materials. When these immiscible fluids are subjected to certain conditions including agitation in the presence of emulsifying agents, an emulsion is formed. The energy input for the formation of crude oil emulsions during oil production is provided by vigorous agitation of oil-water mixture at points such as perforations, gas lift mandrels, wellbore valves/chokes, bends along flow line, separators and pumps (HTS Consultants, 2004)

An emulsion is usually defined as a dispersion of a liquid within another. In this case of oil and water, the water can be dispersed in the oil (water in oil emulsion) or the oil dispersed in the water (oil in water emulsion). They can be stable, meso- stable and unstable depending on their rheological properties and ease of separation (Odisu and Salami, 2010). The water is undesirable because it creates several problems in production, transportation, and processing processes. These problems may include: increased cost of pumping, significant flow line or tubing pressure resulting from high viscosity emulsions, and significant pressure drops created in flow lines. These problems evidently translate into huge cost to the oil industry and hence to the global economy in terms of the risk of corrosion of export and subsea pipelines and refining equipment, possible catalyst poisoning, increased crude oil pumping costs and other associated problem (Odisu and Ebewele, 2008). There is therefore urgent need to give more attention to the study of the process or processes that may lead to the formation of emulsion, the properties of emulsions and ways of destabilizing or separating emulsions. This will enhance more efficient design and operational flexibility of production and separation systems.

The process of stabilization/destabilization of waterin- oil emulsions is a complex field with great implications for petroleum processing. The destabilization process can be achieved by using one or a combination of methods including gravity

* Corresponding Author Email: teddyodi2002@yahoo.com 
settling (centrifugation), application of heat, electrical methods and chemical methods involving application of chemical demulsifiers. The settling tanks, cyclones, centrifugal separators and other kinds of mechanical separation tools in the destabilization of crude oil emulsions is considerably voluminous as well as expensive to install on offshore platforms and even on land operation stations (Petroleum extension service, 1974). It means great economic benefit whenever the installation can be kept at a minimum size and number. The use of chemicals called demulsifiers has become common for destabilizing emulsions and it has also been confirmed that alcohols have the capacity to enhance the performance of demulsifiers in the destabilization of crude oil emulsions (Sjoblom et al, 1992; Siffert et al, 1994)

Therefore, the objective of this study is to investigate the effect of branched and straight chained alcohols on the performance of demulsifiers.

\section{MATERIALS AND METHODS}

Three (3) $100 \mathrm{ml}$ measuring cylinders (Pyrex, England) containing emulsion samples (obtained from flow stations around the Niger Delta) were placed in water bath (Optichem by Chemglass, New Jersey) and heated at a temperature of $30^{\circ} \mathrm{C}$ and $60^{\circ} \mathrm{C}$ each for 10mins and then removed. Subsequently, 10 ppm of the sample demulsifier-sample CD-A (obtained from an oil field chemical application company in Warri, Nigeria) was added to the different crude oil samples (A, B and C) using a micro pipette. Thereafter, $10 \mathrm{ppm}$ of methanol, ethanol and propanol (obtained from chemical vendor in Warri) were added separately to each of the crude oil emulsion samples already having demulsifiers.

The samples were observed for $10 \mathrm{mins}, 20 \mathrm{mins}$ and 30mins according to ASTM D1401-98. The observation period was extended to $40 \mathrm{mins}, 50 \mathrm{mins}$, 60 mins, 90 mins, 120 mins, 150 mins, and $180 \mathrm{mins}$ because of the time it takes in some cases for crude oil to possibly travel from the point of production and injection to the point of final settling and phase separation.

All the observations were noted and result presented for each temperatures, time, and particular alcohol. The above process was repeated using branched alcohol- propan-2-ol, butan-2-ol, and benzyl alcohol ((obtained from chemical vendor in Warri) - with the same conditions and procedure. The amount of water separated at the different time and temperature was measured and recorded.

\section{RESULTS AND DISCUSSION}

Figures 1a, b and 2c compare the result of demulsification with methanol as performance enhancer at $30{ }^{\circ} \mathrm{C}$, and $60{ }^{\circ} \mathrm{C}$ for the different crude oil samples. After 1440 mins, with the addition of methanol at $30{ }^{\circ} \mathrm{C}$ and $60{ }^{\circ} \mathrm{C}$, sample $\mathrm{A}$ gave an amount of separable water of $1.6 \mathrm{ml}$ and $4 \mathrm{ml}$ respectively while in the case without alcohol at 60 ${ }^{\circ} \mathrm{C}$, we have $2 \mathrm{ml}$. Sample B gave $3.6 \mathrm{ml}$ and $16 \mathrm{ml}$ at $30{ }^{\circ} \mathrm{C}$ and $60{ }^{\circ} \mathrm{C}$ and without alcohol at $60{ }^{\circ} \mathrm{C}$ it yielded $3 \mathrm{ml}$. However, sample $\mathrm{C}$ gave $2.4 \mathrm{ml}$ and 4 $\mathrm{ml}$ while without alcohol at $60{ }^{\circ} \mathrm{C}$ gave $0 \mathrm{ml}$. The results show a trend of relative improvement with the addition of methanol particularly for the case of sample C. These also suggest that the effect of the straight chain alcohol - methanol on the demulsification process will be better off at higher temperatures. The reason for this may be that the alcohol functional group in methanol could interact with $\mathrm{OH}$ in water to enhance the hydrophilic action of the demulsifier or increase the water-oil partitioning that could result in enhanced separation of the water from oil

Figures 1c, $d$ and $2 \mathrm{c}$ show the effect of addition of ethanol at $30{ }^{\circ} \mathrm{C}$ and $60{ }^{\circ} \mathrm{C}$ as well as the control. After 1440 mins, with the addition of ethanol at $30^{\circ} \mathrm{C}$ and $60{ }^{\circ} \mathrm{C}$, sample $\mathrm{A}$ and $\mathrm{C}$ gave separable water of $2.4 \mathrm{ml}$ each and the control at $60{ }^{\circ} \mathrm{C}$ gave $2 \mathrm{ml}$ and 0 $\mathrm{ml}$ respectively. Sample B gave $12 \mathrm{ml}$ at $30^{\circ} \mathrm{C}$ and $13.5 \mathrm{ml}$ at $60{ }^{\circ} \mathrm{C}$ and without alcohol at $60{ }^{\circ} \mathrm{C}$ it yielded $3 \mathrm{ml}$. However, sample $\mathrm{C}$ gave $2.4 \mathrm{ml}$ and 4 $\mathrm{ml}$ while without alcohol at $60{ }^{\circ} \mathrm{C}$ gave $0 \mathrm{ml}$. This again shows a relative increase in amount of recoverable water on addition of an alcohol especially this time for B and C. The impact was still minimal for A. This could be attributed to the fact that the activity of the $\mathrm{OH}$ functional group present in the ethanol enhancing hydrophilic and hydrophobic actions. Figures $2 \mathrm{a}, \mathrm{b}$ and $\mathrm{c}$ show the effect of the addition of propanol at $30{ }^{\circ} \mathrm{C}$ and $60{ }^{\circ} \mathrm{C}$ on the demulsification process and the case of no alcohol. The results show that after 1440 mins, samples A, gave $2 \mathrm{ml}$ and $6 \mathrm{ml}$ respectively and $2 \mathrm{ml}$ for the case without. Sample B yielded $14 \mathrm{ml}$ and $11.8 \mathrm{ml}$ and 3 $\mathrm{ml}$ for control. Sample C gave $5 \mathrm{ml}$ and $5.6 \mathrm{ml}$ at the two temperature conditions with $0 \mathrm{ml}$ for control. Even at $60{ }^{\circ} \mathrm{C}$. The results at the two temperatures when compared to the control case, suggest that effect of Propanol was more obvious for samples B and $\mathrm{C}$ irrespective of operating temperature, while the effect for case A seems minimal. The enhanced performance again could be attributed to activity of the $\mathrm{OH}$ functional group present in the ethanol. 

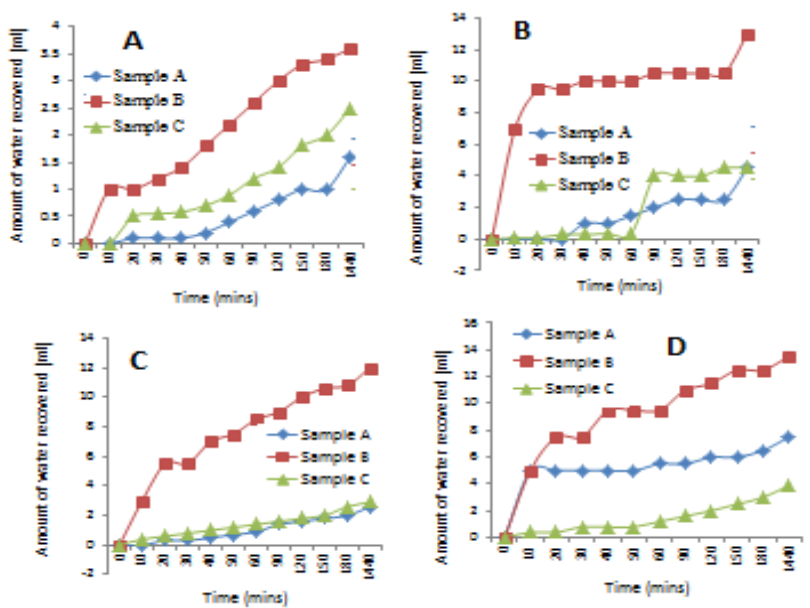

Fig 1: Graph showing amount of water separated with time for methanol at (a) $30^{\circ} \mathrm{C}$, (b) $60{ }^{\circ} \mathrm{C}$, ethanol at (c) $30^{\circ} \mathrm{C}$ and (d) $60^{\circ} \mathrm{C}$

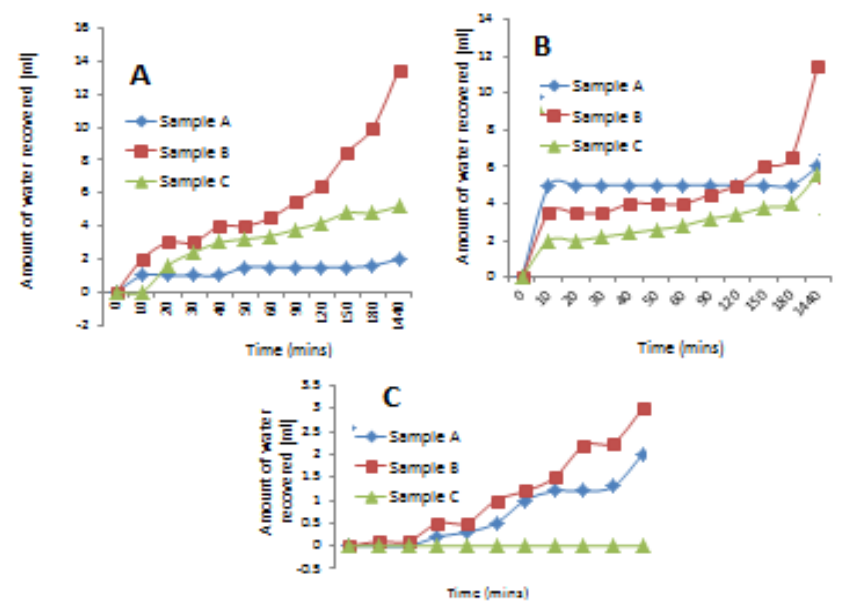

Fig 2: Graph showing amount of water separated with time for Propanol at (a) $30^{\circ} \mathrm{C}$, (b) $60{ }^{\circ} \mathrm{C}$ and (c) without alcohol
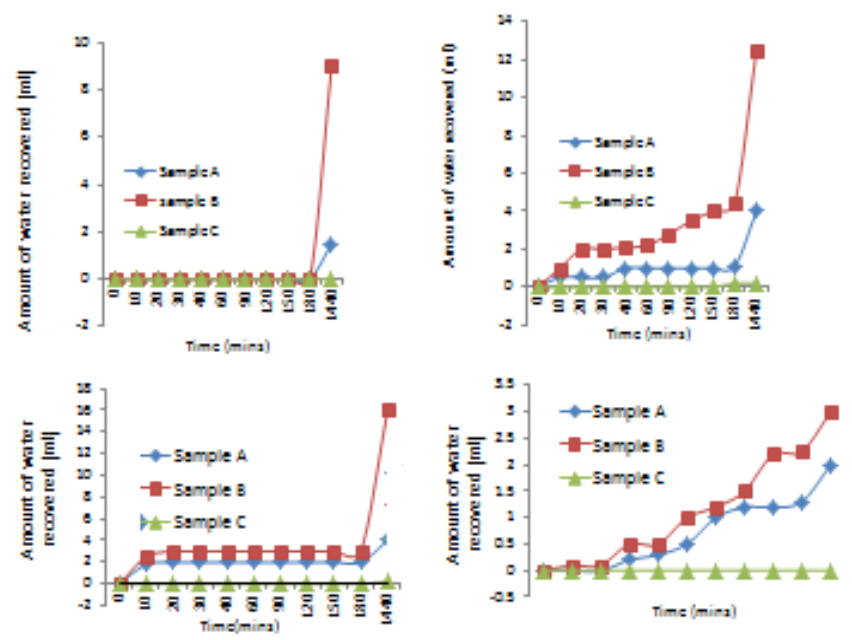

Fig 3: Graph showing amount of water separated with time for Propan-2-ol at (a) $25^{\circ} \mathrm{C}$, (b) $30^{\circ} \mathrm{C}$, (c) $60{ }^{\circ} \mathrm{C}$ and (d) without alcohol
Abdurahman et al , 2007 concluded that the performance of all demulsifiers either water or oil separation can be enhanced by addition of alcohols and that using alcohols alone did not resolve the emulsion implying that the alcohols only enhanced the activities of demulsifiers. It has been observed that as the molecular weight of the alcohol increases, their enhancing effect increases. Alcohols with low chain $\left(\mathrm{C}_{1}\right.$ to $\left.\mathrm{C}_{3}\right)$ are soluble in water, while $\mathrm{C}_{4}-\mathrm{C}_{6}$ are partially soluble and long chain $\mathrm{C}_{7}$ and above are insoluble (Nuraini et al, 2011; Al-Sabagh, 2011). These positions are in line with our observation as the three straight chain alcohols used show a relative increase in enhancement activity from methanol to propanol. Figures $3 \mathrm{a}, \mathrm{b}, \mathrm{c}$ and $\mathrm{d}$ compare the results of demulsification with propan-2-ol as performance enhancer at $25{ }^{\circ} \mathrm{C}$, $30{ }^{\circ} \mathrm{C}$, and $60{ }^{\circ} \mathrm{C}$ for the different crude oil samples with the control (3d). With the addition of the alcohol at $25{ }^{\circ} \mathrm{C}$, samples $\mathrm{A}, \mathrm{B}$, and $\mathrm{C}$ maintained their stability until the $1440^{\text {th }}$ minute when $A$ gave 2 $\mathrm{ml}$; B recorded $9 \mathrm{ml}$, with no water obtained from $\mathrm{C}$. However, without alcohol at $30^{\circ} \mathrm{C}$, for samples $\mathrm{A}, \mathrm{B}$, and $\mathrm{C}$ water separated were $2 \mathrm{ml}, 3$ $\mathrm{ml}$, and $0 \mathrm{ml}$. While at $30^{\circ} \mathrm{C}$ and 60 ${ }^{\circ} \mathrm{C}$, with alcohol, sample A gave 4 $\mathrm{ml}$ each; B gave $13 \mathrm{ml}$ and $16 \mathrm{ml}$ each; $\mathrm{C}$ gave $0 \mathrm{ml}$ for each temperature. The results show that the alcohol did not affect the process too well except for the case of sample B. Suggesting that the effect of the branched alcohol on the demulsification process was slow and minimal except for $\mathrm{B}$ after a relatively long time. The reason could be due to the position of the $\mathrm{OH}$ functional group in propan-2-ol that prevented it's interact with water by enhancing the hydrophilic property of the demulsifier, which have resulted to enhanced oil - water separation (Abdurahman et al, 2007).

ODISU, T; EDOMWONYI-OTU, LC; BASSEY, EN; OHIMOR, EO 

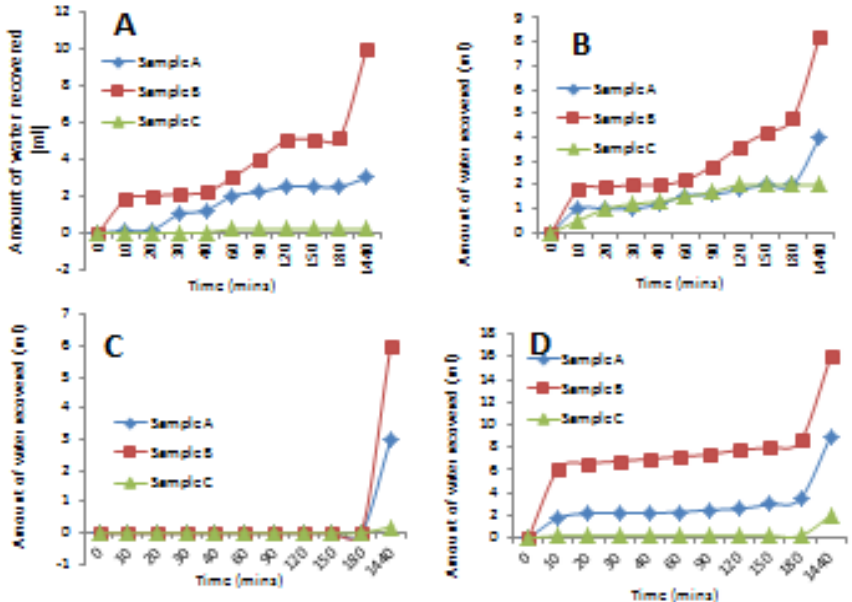

Fig 4: Graphs showing amount of water separated with time for Butan-2-ol at (a) $30{ }^{\circ} \mathrm{C}$, (b) $60{ }^{\circ} \mathrm{C}$ and Benzyl alcohol at (c) $30{ }^{\circ} \mathrm{C}$ and (d) $60{ }^{\circ} \mathrm{C}$

Figures 4a, 4b, and 3d now show the effect of addition of butan-2-ol for the purpose of enhancing the demulsification process. Also, like the case of propan-2-ol, the impact was minimal with $2 \mathrm{ml}$ of water recovered at the first 2 mins while $5 \mathrm{ml}$ after $120 \mathrm{mins}$ and $10 \mathrm{ml}$ after 1440 mins for sample B. Sample A in turn gave $4 \mathrm{ml}$ while $\mathrm{C}$ remained stable at $30^{\circ} \mathrm{C}$. Surprisingly, when the temperature was increased to 60 ${ }^{\circ} \mathrm{C}$, the situation did not improve as the water recovered reduced from $10 \mathrm{ml}$ earlier to $8 \mathrm{ml}$ at $1440^{\text {th }}$ mins for A with B maintaining water recovering of $4 \mathrm{ml}$ and $\mathrm{C}$ without any recovered water. This could still be attributed to the fact that the $\mathrm{OH}$ functional group present in the alcohol could not cause any major impact on the separability of oilwater mixture because of the cloud of bond around it as a result of the $\mathrm{OH}$ position. As highlighted above, compared with the control, it could be considered not to have made significant impact except for sample B. Figures $4 \mathrm{c}, 4 \mathrm{~d}$, and $3 \mathrm{~d}$ show the actions of benzyl alcohol at $30^{\circ} \mathrm{C}$ and $60{ }^{\circ} \mathrm{C}$ on the demulsification process. The result show that at $30^{\circ} \mathrm{C}$, the separation was minimal and slow as well with no observable separation from the beginning to the 180th mins before sample A and B gave $3 \mathrm{ml}$ and $6 \mathrm{ml}$ respectively and non for sample $\mathrm{C}$ after 1440 mins. However, at $60{ }^{\circ} \mathrm{C}$, the separation improved for samples $\mathrm{A}$ and $\mathrm{B}$ with maximum observable water recovered of $8 \mathrm{ml}$ and $16 \mathrm{ml}$ respectively while $\mathrm{C}$ gave about $2 \mathrm{ml}$. This seeming difficulty in separation could still be attributable to the presence of bond cloud around the $\mathrm{OH}$ functional group making it unable to initiate $\mathrm{OH}$-water affinity that could have enhanced oil-water separation. Also when compared to the case for the control set up, we can conclude that the alcohol did not significantly affect the process except for sample B at an increased temperature. The observations are in line with some past works that have suggested that demulsifiers are surface agents and develop or create a high surface area at the crude water/oil interfaces. Al-Sabagh et al, 2011 reported that the increase of available surface area for demulsification happens by the replacement of films of natural crude oil surfactants by a film that is conducive to coalescence of water droplets. Therefore the higher the surface area created the better the enhancement action. This position could well have explained the above observations which suggest that branching did not encourage increase in available surface area by alcohols and therefore, the enhancement effect of branched alcohols on demulsifiers seem limited.

Conclusion: From this study, the straight chain alcohols used showed better potential as performance enhancers for demulsifiers than the branched chains alcohols that were used. Although, the performance of both class of alcohols were found to be affected by crude oil chemistry and possibly demulsifier based components and their effect was not generally drastic (gradual and minimal in some instance). On a general assessment, straight chain alcohols gave better performance enhancement effect than branched chain alcohols whose effect at low temperatures was low and seems to be more affected by changes in crude oil chemistry.

\section{REFERENCES}

Abdurahman, HN; Mohd AA; Rosli MY (2007).

Characterization and Demulsification of Water-incrude Oil Emulsions. https://scialert.net/abstract/?doi $=$ jas.2007.1437.1441, DOI: $10.3923 /$ jas.2007.1437.1 $\underline{441}$

Al-Sabagh, AM; Nadia, G K; Mahmound R N (2011). Functions of demulsifiers in the petroleum industry. Sep sci and Tech 46: 1144-1163
HTS Consultants (2004). Demulsification in Oilfield Production. Chem and Microbio: $1-20$

Nuraini, M; Abduhraman, N; Siti Kholijah, AM (2011). Effect of chemical breaking agents on water in crude oil emulsion system. Inter $\mathbf{J}$ of Chem and Environ Eng 2, (4): 250-254 
Odisu, T; Ebewele, RO (2008). Effect of asphaltene aggregation on crude oil emulsion stability. $J$. Nig Soc of Chem Eng: 86-90

Odisu, T; Salami, D O (2010). Formulation and Production of Demulsifiers Using Locally Sourced Materials. J. Phy. Sci. Innov. 2: 26-37

Petroleum Extension Service (PES) (1974). Treating Oil Field Emulsions. Industrial and Business Training Bureau Division of Extension, The University of Texas at Austin , $3^{\text {rd }}$ Ed: $1-10$
Siffert, BC; Bourgeois E P (1994). Structure and water - oil- emulsifying properties of asphaltenes. Fuel, 63: 834-837.

Sjoblom, J; Urdahl, O; Borve, KCN; Mingyuan, L; Saeten,JO; Christy, AA; Gu, T (1992). Stabilization and destabilization of water in oil crude oil emulsions from the Norwegian continental shelf. Advan in Coll and interf sci 41: 241-271. 